\title{
A Para-text Driven Back-translating of the Diamond Sutra from English to Chinese
}

\author{
Honglei $\mathrm{Hu}^{1}$ \\ ${ }^{1}$ School of Foreign Languages, Jilin Normal Univensity, Changchun, China \\ Correspondence: Honglei Hu, School of Foreign Languages, Jilin Normal University, Changchun, 130103 (zip \\ code), China. Tel: 86-13839421933. E-mail: 2686987108@qq.com
}

Received: February 1, 2016

Accepted: February 5, $2016 \quad$ Online Published: February 26, 2016

doi:10.20849/ajsss.v1i1.15

URL: http://dx.doi.org/10.20849/ajsss.v1i1.15

\begin{abstract}
This thesis is to analyze problems arising out of the rendition of the Sutra, such as limited preparation, time management, knowledge background and translation skills used during the translating process. Psychological aspect of the translator is also discussed in this thesis, esp. the contradiction between the Buddhistic teachings, vegetarianism and physical strength of the translator plus a solution. Cultural aspect of translation is also considered in the thesis. The results of the experience are: knowledge background is the premise to select the best original and pull through the translating; the translator's traits might have a say in the translating dynamics; time management is significantly important in translation; contradicting elements might be resolved by psychological meditation; translating tools and tactics might affect the speed of translation while translation strategy might have an over-riding role during the translation through solving contradiction between ethics and strategy; in turn, the choice is to further clarify the definition of translation and interpretation as a whole.
\end{abstract}

Keywords: background knowledge, translating strategies, culture

\section{Introduction}

Buddhism has constantly been a theme delved into by Chinese, and it's a phenomena of doing things through intricate design, a ubiquitous entity commercializing our life and a mystic attraction urging us to plow headlong for the pursuit of the ultimate truth of Buddhism and life, the thrill of our experience and the mystery of the borderless universe. It trains our reasoning, reminds us of conformity to creeds, enhances our identification and startles up waves of social reform on relations of family and community reform and inspires enlightenment of aspiration for the ideological things which might be attainable for us in future. It also concerns on bigots, wars, terrorism, burning of monks and persecuting of individuals with unconformable feelings or rationale towards nature and religion (Damien, 2000). The Sutra was too archaic (rendered into ancient Chinese in the ninth century), and it was re-translated from Chinese into English by master Hsüan Hua in 1974, that young Chinese readers are not able to construe it properly. So, it's significant to assist them understanding the Sutra.

An experiment is to back-translate the Sutra so as to test perimeters such as optimal version of the source text, strength of the translator, background knowledge, translator's competence, time management, cultural clashes and ethical problems. These perimeters are not tested as other translators are only limited to the linguistic analysis of texts.

It is to research planning, understanding of material, translating and polishing of target language so as to determine the weights of parameters in language rendition.Moreover, translator's traits in time management, dynamics of the translating, attitude towards cultural clashes, strategies adopted in translation are explicated in translating procedures.

It's to make a rough-and-ready hypothesis in translation strategy and its correlation to ethics and culture. It is also to discuss readers' response after the translated material being distributed to them.

That, the experiment will redefine the concept called "translation" through qualitative analysis. It also provides readers with suggestions against pitfalls in English-Chinese Buddhism translation and cultural tips for translator's self-refinement, competence cultivation and elevation of vision towards life, esp. the involvement in the community (Malory, 2008). Their texts are generally static rather than dynamic. This experiment is dynamically flowing from the starting of translation to the revision, thus making the translation procedure as a 
cyclical whole. Gautama Buddha's teachings are reckoned as the core of Buddhism, while the teachings of the Diamond Sutra seems to ask an Arhat to dismiss his practices while adding Bodhisattva as an intermediate stage between an Arhat and a Buddha. According to Xuan Zang in Tang dynasty, Kumàrajãva has omitted the second one of three questions (how to cultivate oneself), one of three gathas (to follow the Dharmakaya could become a Buddha, for Instructors have established themselves by Dharmakaya or "fa shen" in Chinese; the nature of Buddha could not be construed or be guessed out) and three of nine metaphors (In fact four:cloud, black cloud, stars and lamp; but "shadow"is added).

\subsection{Chinese People's Ruts in Translation}

Chinese aging from twenty to sixty are cut off from the past and the international community of civilization. They criticize the text either by distinguishing the literal and the free, the functional and the formal, the foreignization and the localization while insulated from the translating process in details, let alone threading the elements of translation to the whole text.

\subsection{Spoofed by Chomskyan TG}

As they prefer to mechanical comprehension of the text than the effect of response, this experiment is a challenge to their limits. They utilise the Chomskyan transformative grammar to defend their letter-to-letter translation of texts whereas ignoring the true spirit of source text and original. Their texts thus could not come through in communication. Often the readers get more addle-headed after reading as a translator fails to catch the exact meaning of the original or failed to convey it while pleading truthfulness and the exactness to the original. This experiment will test their dos and don'ts so as to clarify the concept called "translation."

\subsection{The Definition of Culture and Translation}

This study focuses on facts in culture and key points supported by the experiment. The first hypothesis goes like this: translation is to make one man understand another man or culture rather than causing hindrance to the understanding. Culture is what human beings as a community get a living by and an identity in it. That is not related to one community could not be called culture. A fish swimming in the pacific ocean or a rat gnawing at a stone at the bottom of 800-meter cave, where never being tread by human from the time immemorial. In terms of the Japanese, a shark in the deep water might means "shark fins". The sentence "a man slips and falls onto the ground" is not culture, for all animals slip and fall. However, when we say "fall onto one's butt", it's culture, in that the butt saves the clumsy man from falling more heavily. Culture differs with interests of ages, social strata, racial groups and gender. The evolution of culture is a three-dimensional network, and sometimes it relapses.

Translating is hypothesized as an activity bridging up gaps between districts, peoples and states. Once there is human being, there is the interpretation of dreams, intentions, reasons and accidents. It concerns translation norms, cultural shocks, gender problems, fidelity, equivalence and others. From the perspective of language, we talk about its content, forms, sounds and meanings and accuracy. From the perspective of translation procedure, we calls to head efficiency, accuracy, efficiency, intentions of initiator and reader's acceptance. From the angle of the translator, we go to fluency, creativity and the invisibility of the "tongue-man". From the aspect of culture, we say traditions, cultural clashes and shocks, identity, misunderstandings and acclimatization. However, translation theories has to be checked for their solidarity in translating practice.Considering new paradigms arising in almost every industry and walk of live everyday: they have a reason to come and we have a reason to test them. Even earth-shaking theories in the ancient time are still in need of checks with today's practice, as time has brought changes to things. Therefore, some theories are seemly attractive and reasonable, we couldn't pay a blind eye to their futility and predictable decline, let alone hailing them.

\section{Method}

\subsection{Overview of Rendition Procedure}

The whole procedure consists of the self-analysis of competence, the preparation, the translating details, the bilingual-format of text and the collating stage.As the translator is defined by his identity, his cultural values are discussed It's to study the possibility of text-fabrication, Kumàrajãva's rendition of the Sutra and the time when the Diamond Sutra was circulating in the secret school of Tibet by comparing them with Gautama Buddha's teachings. The translator's life and meditation is closely analyzed for accurate depiction of the translating procedure. Climate difference between India and China's hinterland and contrasting concepts of phenomena between the two countries are also put into consideration.

Flows of translation is shown in Figure One. The strategy before translation consists of choosing the optimal version, the hardship of text, the possibility of searching for para-text and translator's self-evaluation of horizon and linguistic competency. After translation, reception is also collected for improving the text. 


\subsection{Subject Characteristics}

Before the translating, The translator has read more than six Buddhism sutras in Chinese in a discrete way in a time-span of eleven years. He had read the Diamond Sutra in ancient Chinese and modern Chinese ten years ago. The translator had practiced sedentary meditation by principles derived from Confucianism, Taoism and Buddhism for over six years (Edward, 2008). Though he hasn't practiced much Buddhism recently, his enthusiasm towards Buddhism has not dwindled to ashes. He believes Buddhism could elevate his spiritual life, though no clear data of correlation is thus derived out of his past practice. He has the confidence for winding out the whole task of translating. However, he has no ambition to become a renown translator. Secondly, he has the motive of entertainment during the process of translating. This means, he is not pressed for carrying out the translating in a limited time. Though the translator claims that he resolves to provide Chinese readers with an easily readable version of the Diamond Sutra, he is not so accountability-bound when the task is initiated.Say, the translator is sanguine for the completion of the task, though he has no clear vision of what strategy of translation might be taken or where the translation might carry him to. He is not working for the reader, or for a publishing house, he is mainly working for entertainment. So, he is ego-centered and attentive in grasping the meaning for the translating of the Diamond Sutra.

Lastly, he presumed that he is the most commensurate artiste for the translation of the Diamond Sutra from English to Chinese, that is, he is whimsical, flamboyant, and sometimes over-confident and charging in doing things, though his actions might carry him to false directions. So, he is practicing what he deems to be related to the Buddhistic culture.

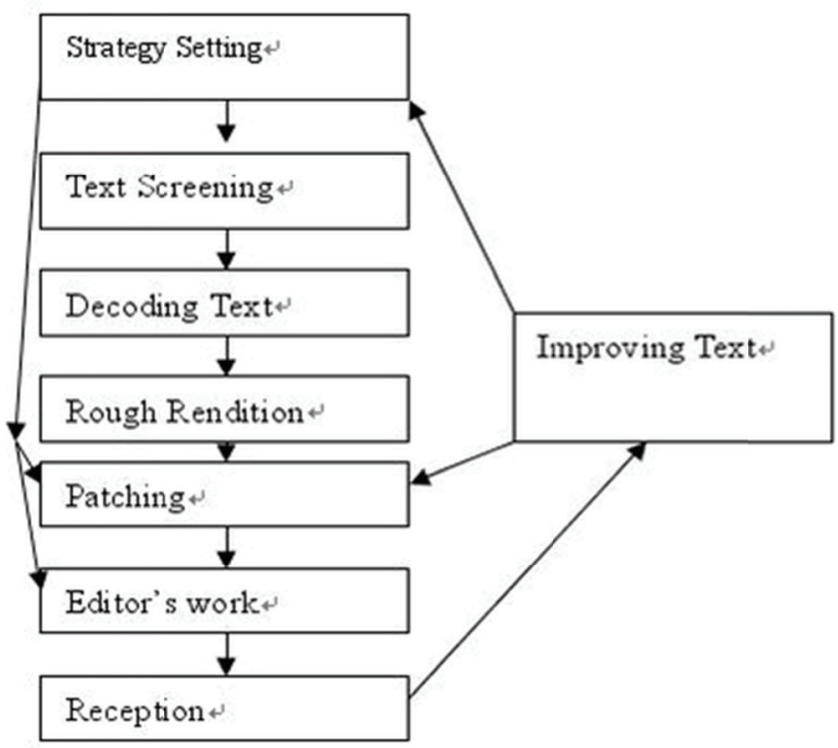

Figure 1. Flow of translation

\subsection{Miscellaneous}

He also collects Sanskrit and Pali sutras presumed to be imparted by the Gautama Buddha himself. His materials also consist of six versions of the Diamond Sutra in ancient Chinese, one translated in modern Chinese with seminar materials of the Sutra by modern Chinese scholars. During the preparation, he is constantly attracted by encyclopedic data on the internet. He tries to collect them and carbonate them on his blogs.Sometimes, he is so ambitious that, he wants to get all materials related to Buddhism to his basket, though they might be irrelevant to the Diamond Sutra. He joins an SMS group for Buddhism sedentary meditation and data hoarding. He also joins Shaolin Kungfu groups and resumes Kungfu exercises.

\subsubsection{Sample Size, Power, and Precision}

He is working with his aged computer and six years of translating experience. Only after having traced the Diamond Sutra, did he find five versions of the Sutra in English. During the translation procedure, he continues hoarding data on Buddhistic principles (Christiane, 2001). Owing to the limit of time, only texts in Chinese and 
English are compared partially. Comparison of other versions are not carried out. His enactment character is conspicuously shown when he tries to keep the gender sequence as it is in the translated text. The translator has not yet found the Buddhist master to check the translated text, so inaccuracy is unavoidably there.

\subsubsection{Measures and Covariate}

At first, key ideas of Buddhism such as catursatya, the Noble Eightfold Path, and the Twelve-fold Chain of Causation (Edward, 2008), the samsara, the cycle of earthly existence, Theravada and Mahayana and Gautama Buddha's four stages of meditation are studied.

The translator has solicited suggestions from peers to get the a better grasp of the original so as to further improve the prosody. This peer-to-peer analysis is a beneficial interaction as it enhances solidarity between translators and improves the translator's competence for better understanding of translator's career, Buddhism and life.

During translating, his practice of vegetarianism gives way to meat so as to maintain physical strength.

\subsubsection{Research Design}

During translating, the translator starts to practice vegetarianism as is stipulated by Chinese Buddhism. He believes the practice helps his understanding of Buddhism in an overall way, though he is attracted by meat.

His comparison focuses on the division of ideas between Xuang Zang and Kumàrajãva by comparing their ideas with Buddha's original ideas. Then, he is to explicate the compared result with the whole humanity as the backdrop.The translator puts the English and Chinese paragraph by paragraph, so that the omission could be checked, consistency ensured and over-abundance reduced.As for the vocabulary, the translator chooses to transcribe the word and convey the meaning with it. For example, the word "Asura" is translated as "Asura the protector of Buddha's law" ("Asura hufa juren" in Chinese) to avoid distracting reader's attention. He puts meaning before the original when expressions in the latter is too esoteric, strange or even completely inscrutable to readers. His annotation is to clarify what remains hindrance to the reader so as to provide an immediate picture of the new term (Eugene, 2002).

\subsubsection{Experimental Manipulations or Interventions}

Sometimes the translator feels weak as he lacks meat nutrition. Therefore, he falls back to meat, though he eats it in a medium amount, one time in three days (Davidson, 2003). Only part of the three versions are compared.

His hoarding of material turns out to be a severe burden at first, as there are too many materials irrelevant to the translating of the Sutra. So he categorized those pertinent to translating into one file-folder for convenience of reference.This method conspicuously speed up the translating.

Annotation is added to the translation for contrasting Buddhism with Jainism as the two religions were closely connected with each other in history. Reference from other sutras is also referred to so as to explicate what one passage is talking about. Contents from Zhuang Tze and other literature are also cited to as Buddhism has already mingled into Chinese culture.In the corresponding annotation to it, Asura's wars with gods and their characters are introduced.

Though gender problem of translation studies are in the favor of the weak gender, the theory still should be carefully checked in its efficacy in solving translating issues. One example is, the lineal sequence in the first chapter of the Diamond Sutra put monks before nuns, laymen before laywomen when enumerating attendants of the Gautama Buddha's seminar. A feminist critic might have suggested putting the weak gender before their counterpart. However, the translator, after analyzing English text and Chinese text, finds that both the two cultures are putting man before woman on their lists of conference attendants, so he decides to leave the sequence as it is. His point is, that ladies are not complaining feeling uneasy after reading the translated draft with gender-sequence as it is (Jeremy, 2001). What's more, two extra gathas rumored to be masterhanded by $\mathrm{Wu}$ Zetian were added as suggested by critics (Malory, 2008; James, 2012).

The translator first distributed his translated material to chatting rooms for peer-reviews. One professional translator of ten years' experience suggests putting the introduction part after the text to let readers get into the text directly. The second translator proposed some rhyme problems for collation. In Chinese, the shorter nominal phrase is before the longer ones while in English the translator finds no such strict stipulation (English deals with similar length syllables). All the two translator's suggestions are accepted by the translator and the translated text, re-examined. 


\section{Results}

\subsection{Time Span of Rendition}

The whole translation is discretely carried out in a time span of one month. The revision takes about one week at first. During writing the thesis, the translator has it re-modified in two days.

\subsection{Xuan Zang Compared with Kumàrajãva}

As is already mentioned in the introduction part, Xuan Zang meted out criticism of omission on Kumàrajãva.During the translating, the author found that the omitted gatha is added by annotation during the spreading of Buddhism. Only Tibetan secret school has names such as "instructors" ("dao shi" in Chinese), who monopolize all the interpretation of sutras. So, in this chapter, the tone depicted by the Diamond Sutra is not Gautama Buddha's, rather, it's a secret school element, who is commenting on this chapter by borrowing the speeches of an instructor. Xuan Zang must have overlooked the adulteration of this part, as his Buddhism is close to the secret school. Dharmakaya, a kind of exorcism to become a living Buddha ("huo fo" in Chinese), is also advocated by their school. The instructor is also preventing his student from understanding Buddhahood: the nature of Buddha could not be construed or be guessed out. So, this gatha is adulterated, hence cut off by Kumàrajãva in Chinese.

As for the metaphors, Kumàrajãva also has a reason to delete them. Stars are constantly in the sky in our daily experience; lamps could be put off and be lit up again; clouds are constantly floating in the sky, sometimes they go, sometimes they come back again, and echoing easiness and loveliness of this life. So, these three symbols are highlighting human controlling over their own life, rather than helplessly resorting to Buddhahood. Black clouds are a specific kind of cloud, but it is more familiar to the tropical citizens than to those in the hinderland of China where there is little rainfall, not to say black clouds.

Moreover, Kumàrajãva has successfully added the image of "shadow" to his metaphor. The addition makes it easy for readers to understand the Sutra: the shadow is not the thing itself as the deviant practice is not the Buddhahood. So, this image is in concord with Buddha's teachings rather than going against it, and it aids readers in understanding.

\subsection{Criticism on Mechanical Comprehension with a Pretext of Literal Exactness and Accuracy}

According to some saying, enlightened beings would retain perceptions whereas with no views (Edward, 2008). However, it is still inadequate to explain why Gautama Buddha cautioned against the scheme of his own cousin who with his caucus of 500 monks split from the sangha. Because in this situation, the Gautama Buddha took a stance and chose to stop schemes to split the sangha and plus a murder to himself. The explanation might be like this: time has adulterated new practices into Buddhism, such as a monk with a wife, the commercialization of Buddhism and political meddling into monk's accounts, though these practices are not allowed by Gautama Buddha himself. Say, the monks has tampered Gautama Buddha's teachings and persuaded the layman to believe in all the words the instructor utters, though the teachings are contradictory to logics, facts and general knowledge (Roy, 1984).

The English version of the Sutra says the Gautama Buddha will "bring all living things to extinction", i.e., the nirvana. But this leaves a loophole for heathen's suicide for nirvana, as it is not permitted by Gautama Buddha if he were still living. After studying the material of Nirvana, we might find that the Gautama Buddha, though having achieved nirvana (with residue when he was thirty-five), was still living to teach the Indian people until forty-five years later when he ate the mushroom by accident and got poisoned to death. Upon "death" he showed his techniques of moving through four stages of meditation, and then he immediately achieved nirvana without residue. One point is to be noted: this death is unintentional and thus not planned (Norman, 2001).

Moreover, the Gautama Buddha, during his life, has never explicated the situation after death as death is the bourne where no one returns. During his lifetime, Gautama Buddha only achieved nirvana with residue. Though he is released from almost all sufferings of life, he had to stay alive in the world to teach the Sangha how to cultivate themselves. Only after his death in 80 , did he live in the nirvana without residue ("wuyu niepan er miedu" in Chinese). But all disciples could not copycat Gautama Buddha as they are not so blessed with so much intellect and merits (Hsüan Hua, 1974).As for the omitted question, i.e., 'how to cultivate oneself', Kumàrajãva has a reason to omit it. For this question is already included in the other two questions: how to resignate to the status quo and be accustomed to Buddha's teachings and how to subdue one's whimsical worries. To "resignate" and to "subdue the heart" is to "cultivate", which is said in the second question. In addition, the word "cultivate" is against Mahayana teachings, as there is no way could be called "to cultivate" ("xiu xing" in Chinese).

Translating method is set to be holistic and integrated with practicable theories and with an eye to assisting the 
reader in understanding the material so as to achieve the aim of translating with efficiency.

Some glitches are still found in the translated text: links such as "moreover" should be replaced by "what's more." Some lines are underscore, which should not be underscored.

His plan to learn Sanskrit has not been realized as circumstances prevented it.

To find the earliest consultancy, choose the right version and do the right thing in the right time in accordance with the procedure are significant for a successful translating. If a translator is too sentimental and emotion-oriented, the turning to reason might have a more gravity in a successful translation than emotion, though affected by tides of sciences and historical policies.

The translator has to keep up to the translating industry and translating studies rather than lagging behind. Materials to be translated have to be recovered in the translator's head to its maximum level by studying relevant materials rather than wasting time on irrelevant materials or getting crucial materials overlooked.

Physical aspect of translator has more say than the spiritual aspect. A background building might cost more time alongside with building up dynamics for rendition. The built-background might mingle in extra information in translating.

Rarely a harmony occurs between the source and target text, especially when restricted by reader's level, time, limited resources and publishing standards.Only an integration of all resources and intellect can a translator achieve refinement in translation.

\section{Discussion}

Suppose the translator has a hazy picture of the three sects of Buddhism, i.e., the primitive, the secret school and the Mahayana, for he has immersed himself the knowledge of Buddhism and tries to abstract as much quintessence as possible. So, he has learned more than is conveyed in the text of the Sutra, which enables him to overlook the Sutra in the context of Buddhism as a whole. This also imposes another work on the translator, i.e., the translator as a teacher, though a translator is not a teacher at all. However, only the translator has far more knowledge than what in implicated in the text, could he properly develop the text in a thorough and clear way to meet the reader's level, rather than making the reader more confused after reading the rendered text. But, a competent translator is not to "develop" a text, it is to translate it.

Considering translator's practice of meditation, he is highly absorbed by Buddha's teachings, and he believes he could get a rich experience through Buddhistic pondering. He only has read the Sutra ten years ago, which might have passed to oblivion and thus being no premise for a successful translation. He only gets the six versions of the Sutra after his hoarding of materials for a long time, which might have prevented him from choosing the best version for translating. That is, he is blindly confident of the experiential perspective to translating the Sutra. Though his enthusiasm might have given him a dynamic in translating, this kind of sub-consciousness might not have urged him to exert his effort but to deviate from the normal procedure of translating. So, he fails in searching for the most appropriate material or working with efficiency. He could have solicited help from specialists in the very first rather than after having finished the translation. He lagging behind in soliciting help has prolonged the translating time span. The rationale only returns to him, temporarily, when he traces the English version of the Sutra and starts categorizing these materials. His differentiation of schools of Buddhism is also out of reason rather than emotion. The rub is that, though he has read Buddhism sutras in Chinese, he only scanned through them to entertain himself. Moreover, his reading of these texts is in a discrete way in a times-pan of eleven years. Addictive to Buddhism and culture of that sort he might be, he has no clear concept of dos and don'ts in Buddhism.

His support of Kumàrajãva bespeaks of his predilection to free translation.His reference of other classics tells us that he takes the cultural bridging perspective of translation. This method has both merits and demerits from the perspective of time-management and information-foci and translating dynamics. His reference of Tibetan secret school, in a wrying tone, also reveals his affinity to primitive Buddhism, rather than to Mahayana or the secret school. So, in him exists a negative dynamic to his translating as the Diamond Sutra falls into the category of Mahayana and to his distaste.

A normal translating procedure often goes like this: scanning through relevant materials, terminology learning and the translating process. That is, he has to glean pertinent information for successful translating rather than otherwise wasting time. He only scans through the Internet to glean knowledge of primitive Buddhism and the secret school. It might have cost him extra time in collecting these extra data. If he were building up background knowledge, he has just spent too much time on it. Though he has already read the Sutra in Chinese, we could not suppose he has grasped the leitmotiff of the Sutra, let alone being ensured of his pre-knowledge of the Sutra. 
When checking his reading list in the bibliography, we find that he has overlooked related sutras for preparation, such as the Lotus Sutra and Suramgama-maha Sutra.

What's more, he might have mingled in extra message into the translated text unawares. We might doubt whether he is truthful to the original text. In order to remedy it, he has to put the translated passages line by line with the original to get inappropriate translations checked and over-abundance reduced. This means a relapsing to literal translation, where coherence and cohesion are negligently put aside.

His translating method is amplification and manipulation. His relapse to meat hints that the "being" aspect of the translator weighs more in translation than experiential reasons.

He is also affected by his country's censure policy in translating the word "nirvana". His gleaning of primitive Buddhism material might have enabled himself to see where Buddha's teaching has been adapted by others after Buddha's nirvana without residue. In his own word, one chapter of the Sutra has been "tampered" by the secret school, for one gatha has the tone of a secret school student rather than the tone of the Buddha. He also presumes that, heathens have crookly skewed the concept of nirvana, i.e., a natural death or a kind of enlightenment while the Sramana Gautama was still living and "saving" the suffering. His caution against tampering of Buddha's teachings also reveals his point of responsibility, i.e., sticking to conveying Buddha's own edicts rather than being kidnapped by fabricators.

\section{References}

Christiane, N. (2001). Translating as a Purposeful Activity: Functionalist Approaches Explained. Shanghai: Shanghai Foreign Language Education Press.

Damien, K. (2000). Buddhism: A Very Short Introduction. Oxford: Oxford University Press.

Davidson, D. (2003). Actions, Reason, Causes. New York: Jounal of Philosophy, 60(23), 685-700. Columbia: Columbia University. http://dx.doi.org/10.1093/0199246270.001.0001

Edward, A. I. (2008). Encyclopedia of Buddhism. New York: Facts on File, Inc.

Eugene, A. N. (2002). Languange and Culture: Contexts in Translation. Shanghai: Shanghai Foreign Language Education Press.

Geshe, L. C., Michael, R., \& Christie, M. (2007). The Diamond Cutter, An Exalted Sutra of the Greater Way on the Perfection of Wisdom. from http://www.buddhism.org/Sutras/DHARMA/Tripitaka/DiamondCutterSutra.htm

Jeremy, M. (2001). Introducing Translation Studies: Theories and applications. New York: Routledge.

Norman, K. R. (1997). Philological Approach to Buddhism. London: Published by the School of Oriental and African Studies (University of London).

Malory, N. (2008). Religion: The Basics. New York: Routledge.

Perrett, R. W. (1984). The problem of inducing Indian philosophy. Philosophy East and West, 34(2), 161-174.

Rajput, D. S. (2015). Indian and World Geography. Retrieved May 12, 2015, from http://developindiagroup.co.in/PDFs/Indian\%20and\%20World\%20Geography.pdf

\section{Copyrights}

Copyright for this article is retained by the author(s), with first publication rights granted to the journal.

This is an open-access article distributed under the terms and conditions of the Creative Commons Attribution

license (http://creativecommons.org/licenses/by/3.0/). 